\title{
Small Populations and Offspring Sex-Ratio Deviations in Eagles
}

\author{
MIGUEL FERRER, ${ }^{*}$ IAN NEWTON, $\dagger$ AND MASSIMO PANDOLFI \\ ${ }^{*}$ Department of Biodiversity Conservation, Estación Biológica de Doñana, Consejo Superior de Investigaciones Científicas, Avenida \\ de María Luisa s/n, Pabellón del Perú, Seville 41013, Spain, email mferrer@ebd.csic.es \\ †Centre for Ecology and Hydrology, Monks Wood Research Station, Abbots Ripton, Huntingdon, Cambridgeshire PE28 2LS, \\ United Kingdom \\ ¥Zoological Laboratory, Urbino University, Via M. Oddi 21, Urbino 61029, Italy
}

\begin{abstract}
Stochastic variation of sex ratio has long been appreciated as a potential factor driving small populations to extinction, but it is not the only source of sex-ratio bias in small populations. We examined whether some consequences of sex allocation could affect extinction risk in small populations of size-dimorphic birds such as eagles. We report variations in sex ratio at fledging from a long-term study of a declining population of Spanish Imperial Eagles (Aquila adalberti). Nestling sex-ratio deviation apparently was mediated by age of breeders, whereas territory quality had no obvious effect. Adult-adult pairs produced the same proportion of both sexes in high-or low-density situations, but pairs with at least one member in nonadult plumage class produced more males. As the population declined over a period of years, the proportion of breeders with immature plumage increased; consequently, the proportion of fledgling males increased. However, when population density was high, the proportion of breeders with immature plumage decreased and more female offspring were produced. This relationship between population density, composition of breeder age, and fledgling sex ratios allowed us to make predictions of extinction risk due to nonstochastic deviations of sex ratio in small, declining populations. In the study population, on the basis of the Vortex simulation results, an estimated reduction of $42.5 \%$ in predicted mean time to extinction was attributed solely to biased sex ratio.
\end{abstract}

Keywords: age of breeding, biased sex ratio, population sex ratio, population decline, population viability, Spanish Imperial Eagle

Poblaciones Pequeñas y Desviaciones en la Proporción de Sexos de Crías en Águilas

Resumen. Por mucho tiempo la variación estocástica de la proporción de sexos ha sido considerada como un factor que conduce a pequeñas poblaciones a la extinción, pero la variación estocástica no es la única causa de sesgo en la proporción de sexos en poblaciones pequeñas. Examinamos sí algunas consecuencias de la asignación de sexo pudiera afectar el riesgo de extinción en poblaciones pequeñas de aves dimórficas como las águilas. Reportamos variaciones en la proporción de sexo de volantones en un estudio de largo plazo de una población en declinación de Águilas Imperiales Españolas (Aquila adalberti). La desviación en la proporción de sexo en polluelos aparentemente fue mediada por la edad de los reproductores, mientras que la calidad del territorio no tuvo efecto obvio. Los parejas adulto-adulto produjeron la misma proporción de ambos sexos en situaciones de alta o baja densidad, pero las parejas con por lo menos un miembro con plumaje no adulto produjeron más machos. A medida que la población declinó en un período de años, la proporción de reproductores con plumaje inmaduro incrementó; consecuentemente, hubo incremento en la proporción de machos volantones. Sin embargo, cuando la densidad poblacional era alta, la proporción de reproductores con plumaje inmaduro decreció y se produjeron más crías hembras. Esta relación entre la densidad poblacional, la composición de la edad de los reproductores y las proporciones de sexo de volantones nos permitió hacer predicciones del riesgo de extinción debido a desviaciones no estocásticas 
de la proporción de sexos en poblaciones pequeñas en declinación. En la población estudiada, con base en resultados de simulaciones con Vortex, una reducción estimada en $42.5 \%$ en el tiempo medio hasta la extinción fue atribuida únicamente a la proporción de sexos sesgada.

Palabras Clave: Águila Imperial Española, declinación poblacional, edad de reproducción, proporción de sexos de la población, proporción de sexos sesgada, viabilidad poblacional

\section{Introduction}

Understanding the demographic processes leading to extinction is fundamental in the management of endangered species. Sex-ratio variation, and its possible consequences to populations, is a central concept in population demography (Le Galliard et al. 2005). Stochastic variation of sex ratio is a potential factor driving small populations to extinction (Gabriel \& Bürger 1992; Courchamp et al. 1999) and is usually included in viability analyses of small populations with sexual reproduction (Ferrer et al. 2004; Rossmanith et al. 2006, 2007). Extinction risk due to sex-ratio variation alone seems relevant only at very small population sizes, but it becomes important when it interacts with stochastically changing population size (Gabriel \& Bürger 1992). Nevertheless, stochastic variation is not the only possible source of sex-ratio bias in small populations (Steifetten \& Dale 2006).

According to Fisher (1930) whenever the sex ratio of a population deviates from equilibrium, any genetic disposition to produce the rare sex will be favored by selection and the ratio will eventually return to equilibrium. The numerical value at the point of equilibrium depends on the relative cost to the parents of rearing each sex. When males and females are equally costly to rear, the population sex ratio should be 1:1, but if they differ in cost, more of the cheaper sex should be produced. Trivers and Willard (1973) were the first to suggest that parents should adjust the sex of their offspring in response to environmental conditions, investing more in whichever sex maximizes their fitness. Based on these ideas, adaptive explanations for sex-ratio variation among vertebrates have been the subject of much debate (e.g., Gowaty 1991; Hardy 1997; West \& Sheldon 2002). Studies on vertebrates, and especially birds and mammals, led to contradictory results (Newton \& Marquiss 1979; Clutton-Brock 1986; West \& Sheldon 2002). In any case the possibility of distortions in the natal sex ratio of birds seems now to be well established (Wiebe \& Bortolotti 1992; Komdeur et al. 1997; Korpimäki et al. 2000), even if the adaptive significance is still obscure in some cases (Heinsohn et al. 1997).

The possible effects of these facultative sex-allocation mechanisms in size-dimorphic species, resulting in sexratio biases, on the viability of small populations have not been analyzed. According to the environmental sex determination hypothesis, for instance, parents in poor conditions (scarce food and poor territories) tend to produce more of the cheaper sex (Trivers \& Willard 1973). Consequently, in an increasing population still with a low density and most of the pairs being able to occupy good territories (e.g., as in a recent colonization), a bias toward the more expensive sex would be expected. In addition, some conservation measures, including supplementary feeding, could affect sex ratio (Tella 2001), increasing again the frequency of the most expensive sex. On the other hand, some authors studying age effects on offspring sex ratio found significant impacts, with younger breeders producing more of the cheaper sex (Blank \& Nolan 1983; Weimerskirch et al. 2000). Consequently, if in a small population the age structure of the breeding component changes, which is likely to occur in eagles (Ferrer et al. 2003), some deviation favoring the cheaper sex (males in this case) would be expected.

Here we report variations in the sex ratio at fledging in a long-term study of a declining Spanish Imperial Eagle (Aquila adalberti) population. We analyzed changes in sex ratio with population level and examined whether these changes could be explained by stochastic variations or whether some other explanation was needed. We included in the analyses factors that are not frequently examined in studies of sex ratio: age of parents, density of population, and territory quality. Our aim was to determine whether facultative sex allocation could increase or decrease the risk of extinction in small, declining populations of size-dimorphic, long-lived birds such as eagles.

\section{Methods}

Species and Population

The Spanish Imperial Eagle is one of the rarest raptor species in the world, with a total estimated population of a little more than 140 pairs (Ferrer 2001). It is a large (2500-3500 g), nonmigratory, and territorial bird of prey, with a low reproductive rate $(0.75$ chicks ' pair ${ }^{-1}$. year $\left.{ }^{-1}\right)$, an immaturity period of $4-5$ years, and an estimated maximum longevity in the wild of up to 21-22 years (Ferrer \& Calderón 1990).

The Spanish Imperial Eagle can be divided into three easily distinguishable plumage classes: juvenile, tawnycolored plumage that remains until the bird is about 3 years old; subadult, dark patches over a tawny base, 
present in birds 4-5 years old; and adult, predominantly dark brown with characteristic white markings appearing at the age of 5 (Ferrer \& Calderón 1990). These differences facilitate the detection of mixed-age pairs (one or both members of the pair in nonadult plumage class). Throughout this paper, we use the term immature to refer to the state of the plumage rather than to reproductive ability.

Data from the eagle population of Doñana National Park (southwestern Spain, $37^{\circ} \mathrm{N} 6^{\circ} 30^{t} \mathrm{~W}$ ) were collected in 1984-2004. During this period, the breeding population ranged between 16 and 7 pairs and the percentage of immature breeders (eagles with nonadult plumage) varied between $3 \%$ and $23 \%$ (Ferrer et al. 2003, 2004). The eagle population at Doñana is apparently separated from other breeding populations: the other nearest nesting conspecifics are $300 \mathrm{~km}$ away (Ferrer 2001).

During the study period, the eagle population showed two distinct phases: 1984-1992, a period of population stability, and 1992-2004, a period of population decrease. After 1992 a dramatic increase in annual adult mortality due to an increase in poisoning in hunting areas surrounding Doñana National Park was recorded. Illegal use of poison against generalist predators accounted for more than $54 \%$ of the number of breeding eagles found dead since 1992, increasing annual adult mortality from $6.07 \%$ to $12.01 \%$ (Ferrer \& Penteriani 2008). This high mortality, affecting breeders but not floaters (Ferrer \& Penterini 2008), reduced the breeding population annually by $6 \%$ during 1992-2004. In 2004 there were only eight pairs, increasing the frequency of immature breeders (Ferrer et al. 2003, 2004).

The park has three main habitat types: Mediterranean scrubland (Halimium spp., Cistus libanotis, Erica spp., scattered cork oaks [Quercus suber], small stone pine [Pinus pinea] woods, and Eucalyptus spp. plantations), marsh (covered mainly by Scirpus spp., flooded in winter, dry in summer), and coastal sand dunes (vegetation mainly of Ammophila arenaria, Corema album, and Juniperus phoenicea). The climate is of Mediterranean type with Atlantic influence.

\section{Data Collection}

We surveyed the study area at the beginning of each breeding season (January-February, during the courtship and nest site selection period; Ferrer 2001) to determine whether pairs were present in the territories. The sedentary behavior of this species and its tendency to call repeatedly greatly facilitate observation of a pair in a territory. Therefore, it is likely that all breeding attempts were detected, as were pairs that did not breed. The territories were surveyed again during the postfledgling period to record the number of fledglings produced per breeding pair. Overall, we knew the number, productivity, and age classes of all breeding individuals for 21 years in Doñana National Park.

\section{Sex Determination}

Nests were also visited to ring the young when they were 45-55 days old. During 1984-1999 sex was determined with a discriminant function analysis that included forearm and tarsus length (Ferrer \& De le Court 1991). Since 2000 we also used a different method to determine sex. We took blood samples when ringing the nestlings and used the cellular fraction to sex the eagles (Ellegren 1996). The analyses were carried out at Doñana Biological Station. During 2000-2004 we determined the sex of 29 nestlings from Doñana National Park. To compare data derived from morphometric sex determination (19841999 period) with data from DNA analyses (2000-2004 period), we calculated the percentage of correct classifications obtained with discriminant function with individuals whose sex was also determined with DNA analyses.

\section{Population Viability Analyses}

We conducted simulation analyses to analyze the effect of sex-ratio bias on population persistence. We used the Vortex simulation software (Vortex, version 9.72, Lacy et al. 2005), which incorporates the effects of environmental and demographic stochasticity, to develop models of population dynamics of Spanish Imperial Eagles in Doñana. Vortex is an individual-based simulation model for population viability analyses (PVA). It models population dynamics as discrete, sequential events that occur according to probabilities defined by the user and as constants or random variables that follow specified distributions. The events used for modeling describe the typical life cycle of a sexually reproducing, diploid organism. The method is particularly suitable for species and populations, such as Imperial Eagles, that have low fecundity, long lifespans, small population sizes, estimable age-specific fecundity and survival rates, and monogamous breeding (Lacy 2000).

\section{COMPARISON SCENARIOS}

Using previously published estimations of fecundity and mortality parameters (Ferrer \& Calderón 1990; Ferrer et al. 2004; Ferrer \& Penterini 2008) we conducted two simulation scenarios. Scenario 1 simulated the trajectory of the Doñana population of eagles since 1992 (decline period) without any bias in sex ratio (i.e., $50 \%$ males). Scenario 2 simulated the trajectory of the same population but with the same sex bias that occurs in the real population (i.e., 2.53 males: 1 female). In both scenarios 1000 replicates were conducted to estimate the effect of sex-ratio bias on population viability. We parameterized the base demographic model and then evaluated model sensitivity to deviation in specific parameters (adult and 
juvenile mortality) by systematically increasing and decreasing the base values of the parameters by $10 \%$ and $20 \%$, respectively. We started the simulations with 16 breeding pairs in the population, the age structure of a stable population ( 45 individuals in total; Ferrer \& Calderón 1990; Ferrer et al. 2004), and a total population ceiling of 200 individuals.

\section{BASE SCENARIO}

Conventions used in the PVA included a monogamous breeding system, a stable age distribution, and breeding by $100 \%$ of adults. Reproduction was assumed to occur at 5 years of age, and the maximum age of reproduction was set to 22 years (Ferrer 2001). Because population density was very low during the simulated period (Ferrer \& Donazar 1996), we considered a density-independent model. To account for environmental stochasticity, we subtracted the expected binomial variance from the total variance estimated from the field data. Following Brook (2000), the expected binomial variance was calculated as

$$
\underline{t}_{t=1}^{Y}[p(1-p) / n-1] / Y,
$$

where $p$ is in each case the rate of fecundity, juvenile mortality, or unpaired or paired eagle mortality, $n$ is the population size at each successive year, and $Y$ is the total number of years of data. Spanish Imperial Eagles have a recorded mean clutch size of 2.47 (SD 0.51) and a mean fecundity of 0.75 (SD 0.23) fledglings $\cdot$ pair $^{-1}$. year $^{-1}$ (Ferrer \& Donazar 1996).

Annual adult mortality rate in Doñana during a long period of population stability was estimated at around $6 \%$ (Ferrer \& Calderón 1990). During 1992-2004, a period of population decline, the annual adult mortality rate was about 12\% (Ferrer \& Penteriani 2008). Annual adult mortality during this last period increased by $100 \%$ relative to the mortality rate of a stable population because of an increase in poisoning in hunting areas surrounding Doñana National Park. Nonadult mortality, however, was similar in both the stability and the decline periods (Ferrer et al. 2004). We considered a population extinct in simulations when only one sex remained. Time simulated was 100 years.

\section{Statistical Analyses}

We conducted two different sets of analyses. The first examined possible causes of sex bias (including parent age, territory quality, and population density). The second examined the effect on the population of the skew in total offspring sex ratio. When analyzing factors affecting sex ratio, the unit we considered was the brood. Within each brood, sex ratio was expressed as number of males/number of nestlings; thus, we avoided pseudoreplication due to autocorrelations inside the brood.
We performed most analyses with generalized linear models (GLM) with binomial distribution and logit link function. Territory and year were treated as random effects to account for possible correlations due to the long life of the eagles and to avoid pseudoreplication. Age of the parents was included as a fixed effect, and brood sex ratio as a dependent variable. The most consistent explanatory model according to the Akaike information criterion (AIC) was selected.

When analyzing the effect of sex-ratio deviations on the population of eagles, we calculated sex ratio as total number of males/total number of nestlings per year. Annual population level was expressed as a percentage of maximum-recorded density from the Doñana population (16 pairs). Territory quality was categorized into three levels on the basis of year of first occupation of territories in a period of population increase (a good indicator of quality, see Ferrer \& Donazar 1996). We used a nonparametric method (chi-square goodness of fit) to compare observed sex ratios against expected ratios under an overall ratio of 1:1. We used the GLM to perform most parametric analyses. The data set was analyzed to evaluate any possible relationships between the percentage of immature breeding birds or population levels and the degree of bias in population sex ratio. All tests were two-tailed, and statistical significance was set at $p<0.05$.

The results of the Vortex simulations were also tested with GLM analyses; we looked for significance of sex ratio as a random factor in distribution of extinction times of replicates. In addition, we used a Wilcoxon matchedpairs test to compare distributions of the number of surviving populations by year between scenarios. All tests were conducted in the STATISTICA 7.0 software packagec (StatSoft, Tulsa, Oklahoma).

\section{Results}

Sex Determination, Fledgling Sex Ratio, and Population Trend

The discriminant function correctly classified all eagle nestlings $(n=29)$ whose sex was also determined from DNA. Thus, sample size for the Doñana population was 115 nestlings in 71 broods over 21 years.

The population remained stable during 1984-1992 at 15-16 breeding pairs. More than 250 breeding attempts were recorded throughout this period. After 1992, with the increase in adult eagle mortality by poisoning, the population declined by about $6 \%$ per year (only eight pairs in 2004; Fig. 1).

Throughout the study period (1984-2004) fledgling sex ratio was not significantly different from 1:1 (66 males, 49 females, $\chi^{2}=2.51, p=0.112$ ). During the period of population stability (1984-1991) sex ratio was not significantly different from 1:1 (23 males, 32 females, 


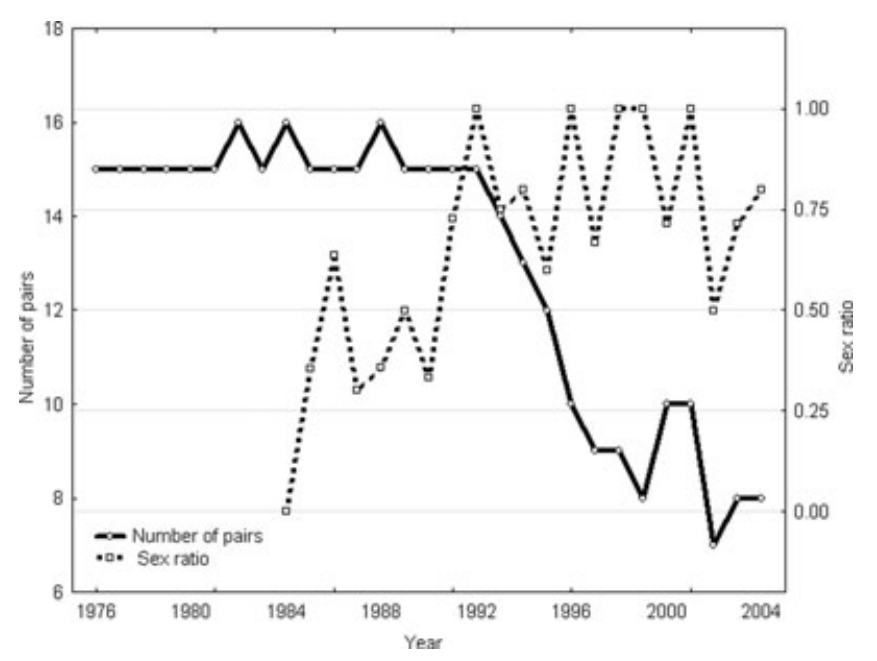

Figure 1. Trajectory of population density and offspring sex ratio (expressed as number of males/total number of nestlings per year) in the Doñana Imperial Eagle population from 1976 to 2004.

$\left.\chi^{2}=1.47, p=0.225\right)$, but during population decline (1992-2004), fledgling sex ratio was significantly biased toward males (43 males, 17 females, $\chi^{2}=11.26, p<$ 0.001 ). Seventy-two percent of the fledglings were male. In both periods the annual sex ratio differed significantly (1984-1991, mean $=0.35 ; 1992-2004$, mean $=0.80 ; t=$ $-5.06, \mathrm{df}=18, p<0.001)$. The annual sex ratio was correlated to the degree of saturation of the population $(r=-0.546, \mathrm{df}=19, p=0.010)$; the number of male offspring increased as breeding pair numbers declined from their maximum historical level.

Within-Brood Sex Ratio, Parental Age, and Territory Quality

Over the study period, $20.5 \%$ of breeding attempts recorded were by mixed-age pairs (at least one member in nonadult plumage class) involving 69 immature breeding birds. The frequency of breeders with immature plumage varied over the years. It was highest in 2001 , when mixed pairs represented $42.8 \%$ of all breeding pairs and individuals with immature plumage reached $30 \%$ of all breeders. The percentage of immature breeders rose significantly between 1984 and 1991 and between 1992 and 2004 (1984-1991, mean [SD] = 4.14\% [2.09]; $1992-2004$, mean $=21.90 \%$ [1.64]; $F_{1,19}=44.51, p<$ 0.001 ), and the annual proportion of immature breeders to total breeders was significantly related to the annual mean of the within-brood sex ratio of fledglings ( $r=$ $0.578, \mathrm{df}=19, p=0.005$; Fig. 2 ). The preponderance of male offspring in the broods increased in parallel with the increasing percentage of immature breeders.

Among data from adult-adult pairs alone, the withinbrood sex ratio during the period of population stability did not differ significantly from the ratio during the pe-

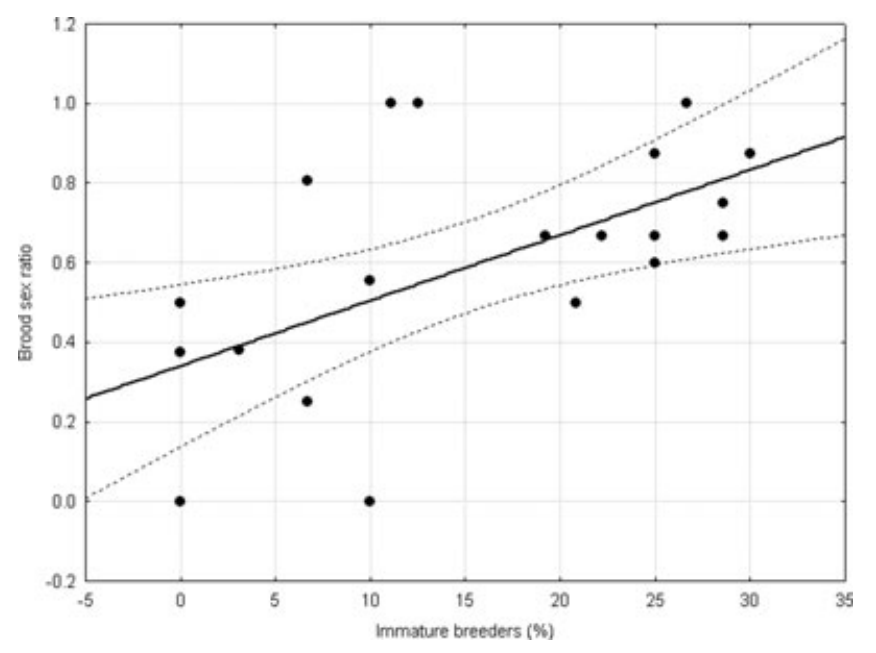

Figure 2. Relationship between percentage of immature breeders in the population and within-brood offspring sex ratio $(r=0.564, d f=19$, $\mathrm{p}=0.007)$.

riod of population decline (GLM with binomial distribution and logit link; 1984-1991 mean $=0.421 ; 1992-2004$ mean $=0.500$; Wald statistic $=0.164, p=0.684$ ).

For mixed-age pairs, the distribution according to the sex of the immature breeder was 15 pairs of a male adult with a female immature, 5 pairs of an immature male with an adult female, and 3 pairs in which both sexes were immature. Brood sex ratio did not differ significantly among the three types of mixed-age pairs (GLM binomial distribution and logit link; Wald statistic $=0.0006, p=0.916$ ), but these results must be taken with caution because of the small sample size and the consequent low power of the test.

During the entire study period, the within-brood sex ratio differed between adult-adult pairs and pairs with at least one immature partner (GLM binomial distribution and logit link; Wald statistic $=8.736, p=0.003$ ), with a predominance of males in the broods of mixed-age pairs (mean brood sex ratio: adult-adult pairs $=0.445$, mixedage pairs $=0.862$ ). The mean sex ratio in the brood and fecundity by territory were not related $(r=0.382$, df $=$ $13, p=0.159)$. Fecundity among territories differed significantly (ANOVA, $F_{2,12}=6.642, p=0.011$ ) within the three levels of habitat quality. Nevertheless, no differences in the mean brood sex ratio among the categories of territories were evident (ANOVA, $F_{2,12}=2,215, p=$ 0.151).

The main effects of the GLM showed that only age of breeders had significant effects on brood sex ratio; males predominated within the broods of mixed-age breeders (GLM binomial distribution and logit link; Wald statistic $=11.068, p<0.001)$. The AIC showed that the most consistent explanatory model was the one that included only parental age (Table 1). 
Table 1. Results of generalized linear model of sex ratio in Spanish Imperial Eagles in which brood sex ratio was the dependent variable (binomial distribution and logit link function). ${ }^{a}$

\begin{tabular}{lllrrrr}
\hline Step & Var. 1 & Var. 2 & Var. 3 & $d f^{b}$ & AIC & \multicolumn{1}{c}{$\Delta A I C$} \\
\hline 1 & parent age & & & 1 & 146.449 & 0.000 \\
2 & year & parent age & 15 & 158.009 & 11.560 \\
3 & territory & parent age & 19 & 163.141 & 16.692 \\
4 & territory & year & parent & 18 & 164.636 & 18.187 \\
& & & age & & & \\
5 & year & & 33 & 166.234 & 19.785 \\
6 & territory & year & & 14 & 177.165 & 30.716 \\
7 & territory & & 32 & 177.347 & 30.898
\end{tabular}

${ }^{a}$ Abbreviations: var, variable; AIC, Akaike information criterion.

${ }^{b}$ Degrees of freedom truncated for presentation.

${ }^{c}$ The best-fitted model included only age of the parent according to AIC.

The percentage of immature breeders by territory category was significantly related to the mean sex ratio of offspring ( $r=0.545$, df $=13, p=0.035)$. There were relatively more fledgling males in territories with more immature breeders. Comparisons of brood sex ratios of adult-adult pairs and mixed-age pairs in the same territory differed significantly (Wilcoxon matched-pairs test; $Z=$ $2.240, n=15, p=0.025)$. Consequently, fledgling sex ratio seemed to depend more on age of breeders than on features of the territory. Sex ratio within the brood was not significantly related to brood size (Kruskal-Wallis, $p=0.591)$.

\section{Simulation Results}

Time to extinction of the 1000 simulated populations was significantly longer for populations with a sex ratio of $50 \%$ males than for populations with a sex ratio of $72 \%$ males (Wald statistic 170.97, $\mathrm{df}=1, p<0.001$ ). The mean time to extinction was 20 years with sex ratio of $50 \%$ males versus 11.5 years with sex ratio of $72 \%$ males (i.e., a $42.5 \%$ decrease in the mean persistence time because of biased sex ratio) (Table 2).

The number of surviving populations per year differed significantly between scenarios (Wilcoxon matched pairs test; $Z=7.167, n=100, p<0.001$; Fig. 3). Consequently, survival of declining populations depended on offspring sex ratio.

Sensitivity analysis showed that populations in both scenarios failed to persist even with an increase of $20 \%$ in adult or juvenile survival (Table 3 ). The abnormally high level of adult mortality due to poisoning in this population explains this result. The mean time to extinction, however, was more sensitive to adult and juvenile mortality than to equivalent distortions in sex ratio (Table 2). With $20 \%$ increases in adult or juvenile mortality, the mean time to extinction decreased by $23 \%$ and $13.5 \%$, respectively, compared with the base scenario. With the same distortion in sex ratio $(+20 \%)$ the decrease in the mean time to extinction was only $5.5 \%$ (Table 2). Nevertheless, the highest decrease in the mean time to extinction was obtained when we used the observed distortion in sex ratio, which was $72 \%$ male offspring. With this level of sex deviation the mean time to extinction was reduced by $42.5 \%$ compared with the base scenario (i.e., a mean time to extinction of 11.5 years with sex bias vs. 20 years in the base scenario; Table 2 ).

Fledgling Sex Ratio and Egg and Chick Mortality

Fecundity parameters differed significantly between adult-adult pairs and mixed-age pairs (Table 3 ), the former having larger clutch sizes, brood sizes, and the mean number of fledglings per nesting attempt than mixed-age pairs. Nestlings produced by adult-adult pairs suffered $17.9 \%$ of nestling mortality, whereas nestlings produced by mixed-age pairs suffered $14.3 \%$ mortality (Table 3 ). If all the chicks that died were females, the ratio of males to females would have been $13 / 8$ among pairs in which one

Table 2. Result of population viability analysis of simulated populations of Spanish Imperial Eagles. ${ }^{a}$

\begin{tabular}{|c|c|c|c|c|}
\hline Base $+20 \%$ sex ratıo & 60 & 1.000 & 18.9 & $-0.089(0.424)$ \\
\hline Base and real sex ratio & 72 & 1.000 & 11.5 & $-0.140(0.325)$ \\
\hline Adult mortalıty +10\% & 50 & 1.000 & 18.5 & $-0.096(0.418)$ \\
\hline Adult mortalıty $-20 \%$ & 50 & 0.993 & 24.3 & $-0.068(0.409)$ \\
\hline Juvenile mortality +10\% & 50 & 1.000 & 18.0 & $-0.100(0.411)$ \\
\hline Juvenıle mortalıty + 20\% & 50 & 1.000 & 17.3 & $-0.123(0.407)$ \\
\hline Juvenile mortality -10\% & 50 & 1.000 & 21.8 & $-0.099(0.421)$ \\
\hline Juvenile mortality -20\% & 50 & 0.994 & 24.3 & $-0.067(0.416)$ \\
\hline
\end{tabular}

${ }^{a}$ Model output includes the extinction probability by 100 years, the mean time to extinction in years, and the population growth rate ( $\mathrm{r}$ and $S D)$.

${ }^{b}$ References each simulation. 


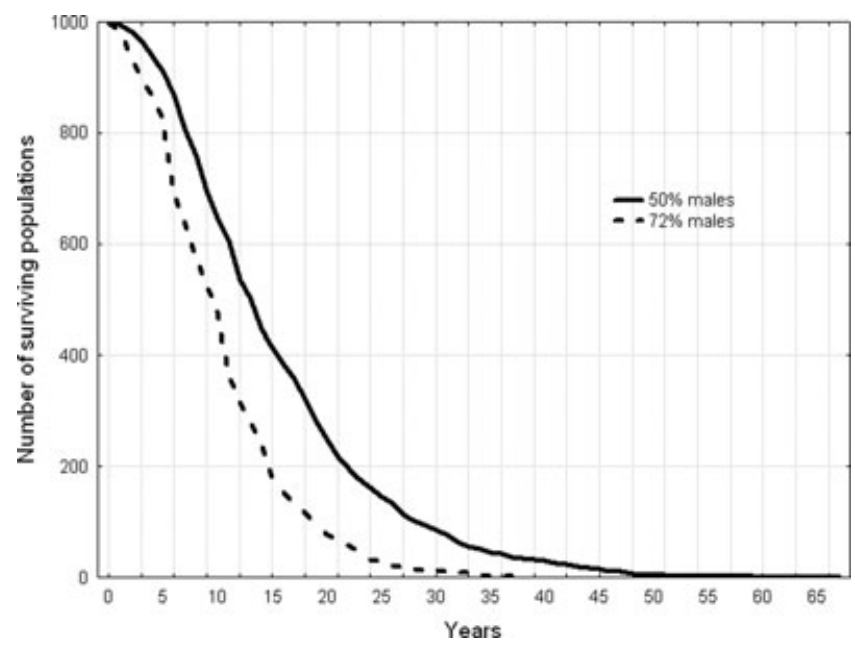

Figure 3. Trajectories of extinction of simulated population of Spanish Imperial Eagles with and without biased sex ratios.

or both partners were immature compared with $47 / 45$ among pairs in which both partners were adults (Fisher exact test, $p=0.059$ ). Therefore, differential mortality in nestlings did not wholly explain the predominance of males among offspring of immature breeders.

Similarly, $45.4 \%$ of eggs laid by adult-adult pairs subsequently hatched, compared with $18.9 \%$ of eggs laid by pairs in which one or both partners were immature (Table 3). If all the eggs that did not hatch were females, the ratio of males to females would have been 19/108 among pairs in which one or both partners were immature compared with $47 / 45$ in adult-adult pairs (Fisher exact test, $p<0.001$, with significant predominance of females among mixed-age pairs). Consequently, a hypothetical differential mortality in eggs could wholly explain the predominance of males among offspring of immature breeders.

\section{Discussion}

We found a sex-ratio deviation at the population level in the Imperial Eagles we studied. To our knowledge this has not been reported previously in monogamous species

Table 3. Differences in fecundity parameters of Spanish Imperial Eagle breeders of different ages (nonparametric Mann-Whitney $U$ test).

\begin{tabular}{lcccc}
\hline Fecundity & $\begin{array}{c}\text { Clutch } \\
\text { size }\end{array}$ & $\begin{array}{c}\text { Eggs } \\
\text { hatched } \\
(\%)\end{array}$ & $\begin{array}{c}\text { Brood } \\
\text { size }\end{array}$ & $\begin{array}{c}\text { Nest } \\
\text { mortality } \\
(\%)\end{array}$ \\
\hline $\begin{array}{l}\text { Adult-adult } \\
\quad \text { pairs }\end{array}$ & 2.06 & $45.44(1.07)$ & 17.93 & 0.88 \\
$\begin{array}{l}\text { Mixed pairs* } \\
p<0.001\end{array}$ & 1.00 & $18.93(0.48)$ & 14.28 & 0.41 \\
& 0.038 & 0.004 & 0.943 & 0.012 \\
\hline
\end{tabular}

*Includes immature-immature pairs. because most studies of sex-ratio deviations in birds examined intrabrood (Wiebe \& Bortolotti 1992) or seasonal deviations (Dijkstra et al. 1990). The skewness in sex ratio in Spanish Imperial Eagles was related to age of the parents. In contrast, no clear effect of territory quality on within-brood sex ratio was found. Adult-adult pairs produced the same proportion of both sexes in high- or low-density situations, but pairs with at least one subadult member produced more male offspring, the smaller and cheaper sex. A possible explanation for male-biased production of mixed pairs is the sex-biased mortality, with more young females dying during the nestling period. Because they grow more rapidly to a larger size as fledgings, nestling females may have greater food needs than males. Nevertheless, only a hypothetical differential mortality in eggs - but not in nestlings - could wholly explain the predominance of males among offspring of immature breeders.

Age of first breeding in this species is densitydependent (Ferrer et al. 2004), so when the population falls below capacity level, the proportion of immature breeders increases (Ferrer et al. 2003). With high population density and a stable number of breeding individuals, the mean age of breeders increases, so immatureplumaged birds are forced to wait to mate or disperse (Ferrer et al. 2004). As proportion of immature breeders in a population increased the proportion of fledgling males increased. When population density was high, however, immature breeders decreased and more female offspring were produced, bringing the nestling sex ratio closer to unity. This relationship allowed us to make predictions about the effect of population density on nestling sex ratios.

In the Spanish Imperial Eagle, as in many other birds (Newton 2008), the female is the most dispersive sex (Ferrer 2001). Hence we can predict that when an eagle population is below saturation level and many territories are vacant, the most philopatric sex will tend to "overproduce" because of an increase in the number of mixedage breeding pairs (Ferrer et al. 2003, 2004). Conversely, when the population is saturated, the most dispersive sex will tend to overproduce because of an increase in age of the breeders. These consequences of the relationship between age and sex ratio will have different effects depending on the metapopulation situation. If the population is relatively isolated and decreasing, overproduction of the most philopatric sex increases extinction risk (a $42.5 \%$ decrease in persistence time in our case). On the other hand, if the population is well connected with other populations within the same metapopulation, overproduction of the most philopatric sex in low-density situations could increase fitness of individuals, which may decrease age of first reproduction. On the other hand, overproduction of the most dispersive sex at high densities would also decrease the mean age of the breeding population. Early reproduction in life, which increases 
breeding lifespan, may be the major demographic determinant of lifetime reproductive success in long-lived bird species such as eagles (Newton 1989). Thus, any reduction in age at first breeding would be positive for the individual.

The relationship we found between age and sex ratio could explain some results obtained by other authors and some apparent contradictory findings. Environmental sex determination is commonly used to explain intrabrood sex-ratio deviations; parents living in poor conditions (scarce food and poor territories) tend to produce more of the cheaper sex (Trivers \& Willards 1973). Results of several studies support this hypothesis (Wiebe \& Bortolotti 1992; Korpimäki et al. 2000; Wade et al. 2003; Suorsa et al. 2003), but none take parental age into account.

We found no effect of territory quality on brood sex ratio in the Spanish Imperial Eagle, but in many situations, immature breeders tend to be present more frequently in poor territories and seldom or never in the better ones (Ferrer \& Bisson 2003; Ferrer \& Penteriani 2003). Nevertheless, during the study period, the decline of our eagle population due to high adult mortality was so pronounced that the percentage of immature breeders reached the highest values ever recorded among large eagles. Good territories were thus made available to young eagles. It is common in territorial birds for younger breeders to start their reproductive lives in poor territories (Newton 1991, Ferrer \& Bisson 2003), so with an appropriate age distribution by territory, an apparent effect of territory quality on brood sex ratio could emerge that could be partly or entirely an age effect.

In the course of population management of Kakapo (Strigops habroptilus, an endangered flightless parrot that has a large sexual size dimorphism) adult females were provided with year-round supplementary food in an attempt to increases reproductive output. Recorded fertility, however, was low, and seven out of eight fledglings were males. This deviation was interpreted as a demonstration of the environmental sex determination hypothesis, because with unlimited food, adult females produced the most expensive sex (Tella 2001). However, the same author said that the low fertility recorded might be related to senescence of adult females (Clout \& Merton 1998; Tella 2001). An age effect is a plausible alternative explanation.

Another commonly suggested interpretation is that sex ratio is biased toward the sex with the wider or more even dispersal pattern (Clark 1978; Gowaty 1993; Lambin 1994; Taylor 1994; Komdeur et al. 1997). This sex-ratio bias depends on whether the population is at low or high density. In our study the most dispersive sex was slightly overproduced only when the population density was high. In such a case breeder age increases and more female offspring are expected, but the reverse situation is predicted with low population density. Thus these buffer effects could be interpreted as a refinement of Clark's (1978) "local resource competition hypothesis."

Other authors studying age effects on offspring sex ratio found significant effects, with younger breeders producing more of the cheaper sex (Red-winged Blackbird [Agelaius phoeniceus], Blank \& Nolan 1983; Wandering Albatross [Diomedea exulans], Weimerskirch et al. 2000). Unfortunately, papers on the possible effect of age of breeders on nestling sex ratios are scarce.

\section{Conclusions}

Our findings show that fledgling sex ratio could be biased at the population level, and that bias toward the cheaper sex (males for Imperial Eagles) could be related to parental age. Because the mean age of breeders is density-dependent in Spanish Imperial Eagles, sex ratio ultimately may be related to population density.

The variation in parental investment with age could be explained by the optimal age-related investment theory (Charlesworth 1980). A lower residual reproductive value for older parents could explain a stronger investment in the more expensive sex later in life (Trivers 1972). Or perhaps younger parents do not have an opportunity to get into good enough condition to meet energy demands of raising the more expensive sex. Regardless of this possibility the absence of a relationship between territory quality and sex ratio gives little support to this interpretation.

These findings have important consequences for conservation plans. In the current population, with only seven breeding pairs and $72 \%$ of fledglings being male, population reinforcement with young females may help recovery. Decreasing adult mortality, however, must be the main goal because of the large effect of this parameter on population persistence and its secondary effect on sex ratio. A decrease in the mean age of breeders increases the distortion in sex ratio, which decreases the mean time to extinction. Consequently, a program to recover the Doñana population of Imperial Eagles and equilibrate its sex ratio was started in 2006 . This program included 0.5-ha fenced areas in which live rabbits were provided throughout the year to reduce movement of adult eagles outside the park (and thus reduce the risk of poisoning) and three young females were added each year from other populations. The program will continue for several years until breeder age increases enough to avoid large deviations in sex ratio. We predict that in any small and declining population of long-lived, sizedimorphic species in which there is an increase in the proportion of immature breeders, a deviation in sex ratio will occur and it will increase the risk of extinction. Consequently, monitoring of fledgling sex ratios would be an informative component of any conservation plan for such populations. 


\section{Acknowledgments}

We thank K. Sieving and two anonymous referees for their comments that greatly improved a previous draft of this manuscript.

\section{Literature Cited}

Blank, J. L., and V. Nolan Jr. 1983. Offspring sex ratio in red-winged blackbirds is dependent on maternal age. Proceedings of the $\mathrm{Na}$ tional Academy of Science (USA) 80:6141-6145.

Brook, B.W. 2000. Pessimistic and optimistic bias in population viability analysis. Conservation Biology 2:564-566.

Charlesworth, B. 1980. Evolution in age-structured populations. Cambridge University Press, Cambridge, United Kingdom.

Clark A. B. 1978. Sex ratio and local resource competition in a prosimian primate. Science 201:163-165.

Clout, M. N., and D. V. Merton. 1998. Saving the Kakapo: the conservation of the world's most peculiar parrot. Bird Conservation International 8:281-296.

Clutton-Brock, T. H. 1986. Sex ratio variation in birds. Ibis 128:317-329.

Courchamp, F., T. Clutton-Brock, and B. Grenfell. 1999. Inverse density dependence and the Alle effect. Trends in Ecology \& Evolution 10:405-410.

Dijkstra C., S. Daan, and J. B. Buker. 1990. Adaptive seasonal variation in the sex ratio of kestrel broods. Functional Ecology 4:143-147.

Ellegren, H. 1996. First gene on the avian W chromosome (CHD) provides a tag for universal sexing of non-ratite birds. Proceedings of the Royal Society of London Series B 263:1635-1641.

Ferrer, M. 2001. The Spanish Imperial Eagle. Lynx Edicions, Barcelona, Spain.

Ferrer, M., and I. Bisson. 2003. Age and territory quality effects on fecundity in Spanish Imperial Eagle (Aquila adalberti). The Auk 120:180-186.

Ferrer, M., and J. Calderón. 1990. The Spanish Imperial Eagle (Aquila adalberti) in Doñana National Park: a study of population dynamics. Biological Conservation 51:151-161.

Ferrer, M., and C. De le Court. 1991. Sex identification in the Spanish Imperial Eagle. Journal of Field Ornithology 63:359-364.

Ferrer, M., and J. A. Donazar. 1996. Density-dependent fecundity by habitat heterogeneity in an increasing population of Spanish Imperial Eagles. Ecology 77:69-74.

Ferrer, M., and V. Penteriani. 2003. A process of pair formation leading to assortative mating: passive age-assortative mating by habitat heterogeneity. Animal Behaviour 66:137-143.

Ferrer, M., and V. Penteriani. 2008. Nonindependence of demographic parameters: positive density-dependent fecundity in eagles. Journal of Applied Ecology 45:1453-1459.

Ferrer, M., V. Penteriani, J. Balbontín, and M. Pandolfi. 2003. The proportion of immature breeders as a reliable early warning signal of population decline: evidence from the Spanish Imperial Eagle in Doñana. Biological Conservation 114:463-466.

Ferrer, M., F. Otalora, and J. M. García-Ruiz. 2004. Density-dependent age of first reproduction as a buffer affecting persistence of small populations. Ecological Applications 14:616-624.

Fisher, R. A. 1930. The genetical theory of natural selection. Clarendon Press, Oxford, United Kingdom.

Gabriel, W., and R. Bürger. 1992. Survival of small populations under demographic stochasticity. Theoretical Population Biology 41:4471.

Gowaty P. A. 1991. Facultative manipulation of sex ratio in birds: rarely or rarely observed? Current Ornithology 8:141-171.

Gowaty P. A. 1993. Differential dispersal, local resource competition, and sex ratio variation in birds. The American Naturalist 141:263278.
Hardy, I. C. W. 1997. Possible factors influencing vertebrate sex ratio: an introductory overview. Applied Animal Behavior Science 51:217241.

Heinsohn, R., S. Legge, and S. Barry. 1997. Extreme bias in sex allocation in Eclectus parrots. Proceedings of the Royal Society of London Series B 264:1325-1329.

Korpimäki, E., C. A. May, D. T. Parkin, J. H. Wetton, and J. Whien. 2000. Environmental- and parental condition-related variation in sex ratio of kestrel broods. Journal of Avian Biology 31:128-134

Komdeur J., S. Daan, J. Tinbergen, and C. Mateman. 1997. Extreme adaptive modification in sex ratio of the Seychelles warbler's eggs. Nature 385:522-524.

Lacy, R. C. 2000. Structure of the VORTEX simulation model for population viability analysis. Ecological Bulletins. 48:191-203

Lacy, R. C., M. Borbat, and J. P. Pollak. 2005. VORTEX: a stochastic simulation of the extinction process. Version 9.50. Chicago Zoological Society, Brookfield, Illinois.

Lambin X. 1994. Sex ratio variation in relation to female philopatry in Townsend's voles. Journal of Animal Ecology 63:945953.

Le Galliard, J. F., P. S. Fitze, R. Ferrière, and J. Clobert. 2005. Sex ratio bias, male aggression, and population collapse in lizards. Proceedings of the National Academy of Science (USA) 102:18231-18236.

Newton, I. 1989. Synthesis. Pages 441-469 in I. Newton, editor. Lifetime reproduction in birds. I. Academic Press, London.

Newton, I. 1991. Habitat variation and population regulation in Sparrowhawks. Ibis 133(Suppl. 1):46-88.

Newton, I. 2008. The migration ecology of birds. Academic Press, London.

Newton, I., and M. Marquiss. 1979. Sex ratio among nestlings of the European sparrowhawk. The American Naturalist 113:309-315.

Rossmanith, E., V. Grimm, N. Blaum, and F. Jeltsch. 2006. Behavioural flexibility in the mating system buffers population persistence: lessons from the Lesser Spotted Woodpecker (Picoides minor). Journal of Animal Ecology 75:540-548.

Rossmanith, E., N. Blaum, V. Grimm, and F. Jeltsch. 2007. Patternoriented modeling for estimating unknown pre-breeding survival rates: the case of the Lesser Spotted Woodpecker (Picoides minor). Biological Conservation 135:555-564.

Soursa, P., E. Huhta, A. Nikula, M. Nikinmaa, A. Jäntti, H. Hellen, and $\mathrm{H}$. Hakkarainen, 2003. Forest management is associated with physiological stress in an old-growth forest passerine. Proceedings of the Royal Society of London, Series B 270:963-969.

Steifetten, O., and S. Dale. 2006. Viability of an endangered population of Ortolan Buntings: the effect of a skewed operational sex ratio. Biological Conservation 132:88-97

Taylor P. D. 1994. Sex ratio in a stepping-stone population with sexspecific dispersal. Theoretical Population Biology 45:203-218.

Tella J. L. 2001. Sex ratio theory in conservation biology: comment from Tella. Trends in Ecology \& Evolution 16:77.

Trivers, R. L. 1972. Parental investment and sexual selection. Pages 136-179 in D. Campbell, editor. Sexual selection and the descent of man. Aldine, Chicago, Illinois.

Trivers R. L., and D. E. Willard. 1973. Natural selection of parental ability to vary the sex ratio offspring. Science 179:90-91.

Wade J. M., S. M. Shuster, and J. P. Demuth. 2003. Sexual selection favors female-biased sex ratios: the balance between the opposing forces of sex-ratio selection and sexual selection. The American Naturalist 162:403-414.

Weimerskirch H., C. Barbraud, and P. Lys. 2000. Sex differences in parental investment and chick growth in wandering albatrosses: fitness consequences. Ecology 8:309-318.

West, S. A., and B. C. Sheldon. 2002. Constraints in the evolution of sex ratio adjustment. Science 295:1685-1688.

Wiebe K. L., and G. Bortolotti. 1992. Facultative sex ratio manipulation in American kestrels. Behavioral Ecology and Sociobiology 30:379387. 